\title{
Ethical Guidelines for the Clinical Management of Intersex
}

\author{
C. Wiesemann \\ Department of Medical Ethics and History of Medicine, University of Goettingen, Goettingen, Germany
}

\section{Key Words}

Autonomy · Dignity - Disorders of sex development ·

Ethics $\cdot$ Guidelines $\cdot$ Intersex

\begin{abstract}
The clinical management of intersex has undergone a significant change in values. Whereas in former times, benevolent medical paternalism was the rule, today, the patient's right to respect for dignity and self-determination is given priority. This paper discusses ethical considerations shaping the modern therapeutic management of intersex conditions that do not entail acute health risks. It concludes with basic ethical guidelines for clinical practice.
\end{abstract}

Copyright $\odot 2010$ S. Karger AG, Base

\section{Change in Values in Intersex Treatment}

The clinical management of intersex has undergone a significant change in values [Wilson and Reiner, 1998]. Until recently, the primary goal of treatment was to establish sex and gender certainty, mostly through early surgical interventions. Benevolent medical paternalism was the rule. For the sake of psychic gender unambiguousness, parents and patients were mostly not fully in- formed about the nature of the variation and the extent of therapeutic corrections. This so-called optimal-gender strategy has been rightly criticized by intersex activists as well as medical experts for ignoring the patient's wishes and, in general, significantly overestimating the benefits of surgery [Chase, 1998, 2003; Kipnis and Diamond, 1998; Dreger, 1999; Beh and Diamond, 2000].

From former patients we have learned that the harm effected by violation of intimacy and stigmatization can be significant. The 'politics of concealment' [Dreger, 2006] entailed isolation, loss of trust and deprivation of peer support, and severely undermined the parent-child relationship. Although it is not clear how many patients have been traumatized by early-childhood interventions compared to those having benefited from it (the latter presumably being a silent group), the number of persons publicly complaining is high enough to count as severe adverse event and to preclude continuing with the old strategy. Moreover, as patients were not fully informed about and involved in treatment decisions, optimal-gender strategy impedes long-term research thus immunizing itself from criticism. For a large number of intersex conditions, there is an ongoing debate whether earlychildhood surgery increases quality of life as well as sex and gender role satisfaction [Creighton et al., 2001; Thyen et al., 2005].

\section{KARGER}

Fax +4161306 1234 E-Mail karger@karger.ch www.karger.com
(C) 2010 S. Karger AG, Base

$1661-5425 / 10 / 0000-0000 \$ 26.00 / 0$

Accessible online at:

www.karger.com/sxd
Dr. Claudia Wiesemann

Department of Medical Ethics and History of Medicine

University of Goettingen, Humboldtallee 36

DE-37073 Goettingen (Germany)

Tel. +49551 399 006, Fax +49551 399 554, E-Mail cwiesem@gwdg.de 


\section{Ethical Principles of Clinical Practice}

Today, clinical interventions, as a rule, have to be justified by the informed consent of the person involved or by a legal representative. The right to self-determination is acknowledged as fundamental in health care [Council of Europe, 1997; De Lourdes Levy et al., 2004]. The clinical management of intersex makes no exception to the rule. Also, article 12 of the United Nations Convention of the Rights of the Child asserts that 'States Parties shall assure to the child who is capable of forming his or her own views the right to express those views freely in all matters affecting the child, the views of the child being given due weight in accordance with the age and maturity of the child' [United Nations, 1989]. This entails giving the patient utmost control over what will happen to his/her body. Finally, evidence-based therapy strategies rely on the long-term evaluation of patients' views. To achieve this aim, full disclosure of information on diagnosis and treatment is a necessary prerequisite.

The new attitude of openness is facilitated by longterm social changes reducing gender role rigidity and allowing for a wider range of sexual identities. However, as a result, it is less clear today what constitutes a good life with regard to sexual identity, rendering patients' choices even more important.

To this day, some medical experts and a number of former patients challenge early surgery aiming at normal or near normal appearance. They argue that the complexity of gender identity is not adequately considered, that the mutilating and traumatizing effects of treatment are not sufficiently taken into account and that intersex without acute health care risks is not medicine's responsibility at all [Briffa, 2004; see also http://blog.zwischengeschlecht.info]. Other than in the case of medical emergencies, some advocate a moratorium on any feminizing or masculinizing operations before full consent may be obtained from the child [Kipnis and Diamond, 1998]. Yet, as generalized policy, this has been criticized because it undervalues the particularities of the individual case, the needs of the young child and the importance of the parent-child relationship [Wiesemann et al., 2010]. Instead, at any age, decisions should be based on the individual's unique condition and prognosis from a biological and social perspective. Parents, as the child's most important attachment figures and legal representatives, have to be included in the decision-making process [Greenberg, 2006]. Health care professionals should strive for the optimal physical, emotional and social development of the child, trying to maximize the child's and future adult's participation in decision-making on the one hand and a good parent-child relationship on the other [Wiesemann et al., 2010].

Several ethics working groups have developed recommendations for clinical practice. In 2004, an ad hoc group at the Hastings Center for Bioethics called for a multidisciplinary approach, the child's right to know and followup studies [Frader et al., 2004]. A consensus statement on the management of intersex disorders issued by the participants of an International Consensus Conference in 2006, involving pediatric specialists from the United States, Great Britain, Germany, The Netherlands, France, Sweden, Italy, Brazil, Japan, and Australia, endorsed a better understanding of psychosocial issues, and recognizing and accepting the place of patient advocacy [Hughes et al., 2006].

In 2009, an ethics working group within the German Network DSD/Intersex developed an exhaustive catalogue of ethical recommendations. They identified 3 leading ethical principles and rights. Any health care professional dealing with intersex is expected to

(1) 'foster the well-being of the child and the future adult. This includes their bodily integrity and quality of life, particularly with respect to reproductive capability as well as ability to experience sex, and the free development of their personality,

(2) uphold the rights of children and adolescents to participate in and/or self-determine decisions that affect them now or later. This includes the right of the future adult to be comprehensively informed about their condition and about all interventions carried out as well as the multidisciplinary health-care team's obligation to provide the appropriate information and maintain documentation,

(3) respect the family and parent-child relationship. This includes the rights and the duties of the parents to represent their child in the decision-making process and their right to receive professional support and assistance from the multidisciplinary health-care team' [Wiesemann et al., 2010].

A catalogue of recommendations indicates how the patient's right to self-determination and the participatory rights of children should be respected. They give due consideration to how to foster the well-being of the child, how to respect family privacy and how to prevent stigmatization and discrimination of patients and families. 


\section{Basic Ethical Guidelines for Clinical Practice}

Intersex conditions are characterized by complex interactions between biological, psychological, social, and cultural factors, making it necessary to decide on a caseby-case basis. Simple formulas have to be avoided. Instead, the individual characteristics of the child, the family and the social background have to be taken into account in order to maximize the benefits for the child. However, the following guidelines for clinical practice can help to minimize ethical problems in decision-making:

(1) Respect that the patient is the one to decide on her/ his gender identity!

Science has given up the idea that gender identity is fully malleable through surgery, socialization or education. The way gender identity emerges is not fully understood; genetic, hormonal, and psychological factors play a major role. In the long run, the patient is the one to know best who she/he is or wants to be. In a number of intersex conditions, such as $5 \alpha$-reductase deficiency or gonadal dysgenesis, chances are high that a change in gender identity occurs during or after puberty. An intervention in childhood should not deprive the patient of the opportunity to live in the gender she/he chooses later on. Some patients may want to live in an intersex identity rather than a female or male one as adults. An unambiguous gender identity, therefore, is often not a reasonable goal.

(2) Do not advocate measures you would not be willing to fully disclose to the patient, particularly when she/he is grown up!

Intersexuality affects the most intimate parts of children's bodies and children's personalities. A number of former patients have suffered incredibly from the secrecy of intersex treatment. As children, they understood that something very awkward and embarrassing happened to them, but they were not able to understand why. They were deeply ashamed and helpless. As adults, they had difficulties to understand and cope with what had been done to their body and soul. These persons have totally lost confidence in medicine and sometimes also in their parents. A trusting relationship is based on openness and shared decision-making between health care professionals and the patient and her/his parents.

(3) Never decide on diagnostic, treatment or counseling options alone or without thorough knowledge of the physical, psychological and social consequences!

Intersex is by nature an interdisciplinary and multidisciplinary task. Gender identity is formed through ge- netic, hormonal, psychological and social factors. Prognosis of sexual identity is most difficult and should always include psychological and social development. Until today, evidence on the outcome of many therapeutic measures or surgical procedures is insufficient. In order to achieve the best outcome possible, diagnosing, treating and counseling persons with intersex or counseling their proxies should be reserved to specialized and experienced multidisciplinary health care teams.

(4) Do not put esthetics first!

When an intersex condition is discovered in early childhood, parents and health care professionals are mostly and firstly worried about the 'abnormal' appearance of external genitalia. Trying to normalize the external genitalia is an understandable reflex. But there are other and better candidates for recommendable clinical goals, such as preventing suffering or advancing self-confidence in the patient. In some cases, suffering is only a problem of the parents, not of the child; then, parents have to be supported to cope with the situation. Esthetic criteria alone do not create a reasonable justification for an intervention. It has to be considered that today's esthetic surgery may impede tomorrow's patient to change her/his sexual identity and thus create new and more significant problems.

(5) Do not make a freak show out of your patient!

Intersexuality is a rare event in everyday clinical life. Many health care professionals may be curious to learn more about it. However, any examination can deeply hurt the child's and the parents' feelings, particularly if performed without clear indication and without express consent. This can amount to sexual abuse. Any examination and documentation, therefore, has to fully respect the child's dignity and voluntariness to expose her/his intimate parts in front of other people. Language also can hurt the dignity of patients. Some terms, e.g. hermaphroditism, are considered stigmatizing and should be avoided.

(6) Never tell your patient or her/his parents what the patient 'really is'!

Some physicians used to tell their patients that they 'really are' a man, just because a Y-chromosome had been found. But nobody knows what somebody else 'really is', not even scientists. In gender identity, there is not one factor to determine who you are. Gender identity constitutes the core and most vulnerable part of one's personality. It is essential to respect the patient's authority in defining the essence of her/his selfhood.

(7) Be cautious when talking about what is 'normal' or 'abnormal'! 
Intersex comprises a number of syndromes situated at the border of normality and disease. There is an ongoing debate on what constitutes a 'normal' woman and a 'normal' man. This debate is unlikely to come to an end soon, as society and gender roles are constantly changing. For example, homosexuality was formerly treated as a biological and psychological abnormality of sexual development, but is no longer today. Normality in medicine is a biological as well as a social criterion and its meaning is changing over time. The terms 'disease', 'disorder' and 'abnormality' usually imply that medicine is in charge of the condition described. However, with regard to intersex, this reflex should be avoided [Wiesemann et al., 2010]. For example, girls with partial androgen insufficiency syndrome and an elongated clitoris will most certainly not need any 'therapy' before puberty and, as adults, may feel perfectly well in a body that does not fully fit the normal. Therapy should have a significant effect on suffering or help to prevent suffering and should not just serve to normalize from a social point of view.

(8) Help to make intersex treatment better and safer!
Intersex conditions are rare and evidence on longterm outcome is difficult to obtain. For lack of evidence, a number of interventions still have to be considered experimental. Adult gender role satisfaction and quality of life are the most relevant evaluation criteria. Former patients rightly demand that in the future, only those treatments should be applied that have been proven effective and beneficent to the patient in the long run. Thus, it is of utmost importance that treatment options are evaluated regularly and that patients are treated by specially equipped and experienced health care teams. Assistance by patient support groups will increase the quality of research and the data obtained.

An optimal child-oriented policy in the clinical management of intersex is guided by the present and future needs of the child, respects the child as a person, is aware that the child needs parents who accept and respect her or him, acknowledges uncertainty in prognosis, and tries to reduce it. The way health care professionals react to intersex can help to educate the public and to minimize stigmatizing and stereotype attitudes towards gender identity variations.

\section{References}

Beh HG, Diamond M: An emerging ethical and medical dilemma: should physicians perform sex assignment on infants with ambiguous genitalia? Mich J Gend Law 7:1-63 (2000).

Briffa T: Intersex surgery disregards children's human rights. Nature 428:695 (2004).

Chase C: Surgical progress is not the answer to intersexuality. J Clin Ethics 9:385-392 (1998).

Chase C: What is the agenda of the intersex patient advocacy movement? Endocrinologist 13:240-242 (2003).

Council of Europe: Convention for Protection of Human Rights and Dignity of the Human Being with Regard to the Application of Biology and Biomedicine: Convention on $\mathrm{Hu}-$ man Rights and Biomedicine. Orviedo, 1997. http://conventions.coe.int/Treaty/EN/Treaties/html/164.htm (accessed April 28, 2010).

Creighton SM, Minto CL, Steele SJ: Objective cosmetic and anatomical outcomes at adolescence of feminising surgery for ambiguous genitalia done in childhood. Lancet 358: 124-125 (2001).
De Lourdes Levy M, Larcher V, Kurz R; Members of the Ethics Working Group of the CESP: Informed consent/assent in children. Statement of the Ethics Working Group of the Confederation of European Specialists in Paediatrics. Eur J Pediatr 162:629-633 (2004).

Dreger AD: When medicine goes too far in the pursuit of normality. Health Ethics Today 10:2-5 (1999).

Dreger AD: Intersex and Human Rights: The Long View, in Sytsma SE (ed): Ethics and Intersex, pp 73-86 (Springer, Dordrecht 2006).

Frader JE, Alderson P, Asch A, Aspinall C, Davis $D$, et al: Health care professionals and intersex conditions. Arch Pediatr Adolesc Med 158:426-428 (2004).

Greenberg JA: International legal developments protecting the autonomy rights of sexual minorities: who should determine the appropriate treatment for an intersex child?, in Sytsma SE (ed): Ethics and Intersexuality, pp 87-102 (Springer, Dordrecht 2006).

Hughes IA, Houk SF, A hmed SF, Lee PA; LWPES/ ESPE Consensus Group: Consensus statement on management of intersex disorders. Pediatrics 118:e488-500 (2006).
Kipnis K, Diamond M: Pediatric ethics and the surgical assignment of sex. J Clin Ethics 9: 398-410 (1998).

Thyen U, Richter-Appelt H, Wiesemann C, Holterhus PM, Hiort O: Deciding on gender in children with intersex conditions: considerations and controversies. Treat Endocrinol 4: 1-8 (2005).

United Nations: The Convention on the Rights of the Child. New York, 1989. http://www2. ohchr.org/english/law/crc.htm (accessed April 28, 2010).

Wiesemann C, Ude-Koeller S, Sinnecker GH, Thyen U: Ethical principles and recommendations for the medical management of differences of sex development (DSD)/intersex in children and adolescents. Eur J Pediatr 169:671-679 (2010).

Wilson BE, Reiner WG: Management of intersex: a shifting paradigm. J Clin Ethics 9:360369 (1998). 